\title{
EUV microexposures at the ALS using the 0.3-NA MET projection optics
}

\author{
Patrick Naulleau ${ }^{1}$, Kenneth A. Goldberg $^{1}$, Erik Anderson ${ }^{1}$, Jason P. Cain ${ }^{2}$, \\ Paul Denham ${ }^{1}$, Brian Hoef ${ }^{1}$, Keith Jackson ${ }^{1}$, Anne-Sophie Morlens ${ }^{1}$, Seno Rekawa ${ }^{1}$, Kim Dean ${ }^{3}$ \\ ${ }^{1}$ Center for X-Ray Optics, Lawrence Berkeley National Laboratory, Berkeley, CA 94720 \\ ${ }^{2}$ EECS Department, University of California, Berkeley, CA 94720 \\ ${ }^{3}$ SEMATECH, Austin, TX 78741
}

\begin{abstract}
The recent development of high numerical aperture (NA) EUV optics such as the 0.3-NA Micro Exposure Tool (MET) optic has given rise to a new class of ultra-high resolution microexposure stations. Once such printing station has been developed and implemented at Lawrence Berkeley National Laboratory's Advanced Light Source. This flexible printing station utilizes a programmable coherence illuminator providing real-time pupil-fill control for advanced EUV resist and mask development.

The Berkeley exposure system programmable illuminator enables several unique capabilities. Using dipole illumination out to $\sigma=1$, the Berkeley tool supports equal-line-space printing down to $12 \mathrm{~nm}$, well beyond the capabilities of similar tools. Using small-sigma illumination combined with the central obscuration of the MET optic enables the system to print feature sizes that are twice as small as those coded on the mask. In this configuration, the effective 10×-demagnification for equal lines and spaces reduces the mask fabrication burden for ultra-high-resolution printing. The illuminator facilitates coherence studies such as the impact of coherence on line-edge roughness (LER) and flare. Finally the illuminator enables novel print-based aberration monitoring techniques as described elsewhere in these proceedings.

Here we describe the capabilities of the new MET printing station and present system characterization results. Moreover, we present the latest printing results obtained in experimental resists. Limited by the availability of highresolution photoresists, equal line-space printing down to $25 \mathrm{~nm}$ has been demonstrated as well as isolated line printing down to $29 \mathrm{~nm}$ with an LER of approaching $3 \mathrm{~nm}$.
\end{abstract}

Keywords: extreme ultraviolet lithography, synchrotron, variable-sigma illuminator, coherence

\section{INTRODUCTION}

Extreme ultraviolet (EUV) lithography [1] remains a leading candidate for volume production at the 32-nm node. For EUV-based volume production to become a reality around the year 2011, advanced research tools are required today. Initial production tools are expected to have numerical apertures (NA) of 0.25 , thus relevant developmental systems also require 0.25 or higher NAs. The demand for early tools has been met with microfield exposure tools which trade off field size and speed for greatly reduced complexity. Such microfield tools have been crucial to sub-0.2-NA EUV development in the past [2-4] and currently serve as the only source for high-NA EUV printing [5-8].

Source performance, cost, and debris mitigation remain as significant challenges for EUV lithography. The use of synchrotron radiation serves as an effective way to mitigate these risks on developmental tools. Although not well suited for manufacturing applications, synchrotron radiation provides an efficient, well-characterized, debris-free source for such microfield systems operated as shared resources [5,6,8]. A significant issue with synchrotron sources, however, is the intrinsically high coherence of the source $[9,10]$ as compared to the reduced coherence requirements of a lithographic tool. As demonstrated in the past [11], this coherence issue can, however, be overcome through the use of active illuminator components. 
In this paper we describe the latest results from the 0.3-NA EUV microfield exposure station at Lawrence Berkeley National Laboratory's Advanced Light Source synchrotron radiation facility. This static microfield exposure station utilizes SEMATECH's 0.3-NA Micro-Exposure Tool (MET) optic [12,13]. The MET optic is a centrally obscured two-element, axially symmetric $5 \times$-reduction optical system manufactured by Zeiss. The central obscuration has a radius equal to $30 \%$ of the full pupil radius, producing an annular pupil. To support reflective masks with this onaxis system, the mask is tilted by $4^{\circ}$ and the wafer by $0.8^{\circ}$. The MET has a well-corrected field of view of $1 \times 3 \mathrm{~mm}$ at the reticle plane $(200 \times 600 \mu \mathrm{m}$ at the wafer plane).

\section{SYSTEM OVERVIEW}

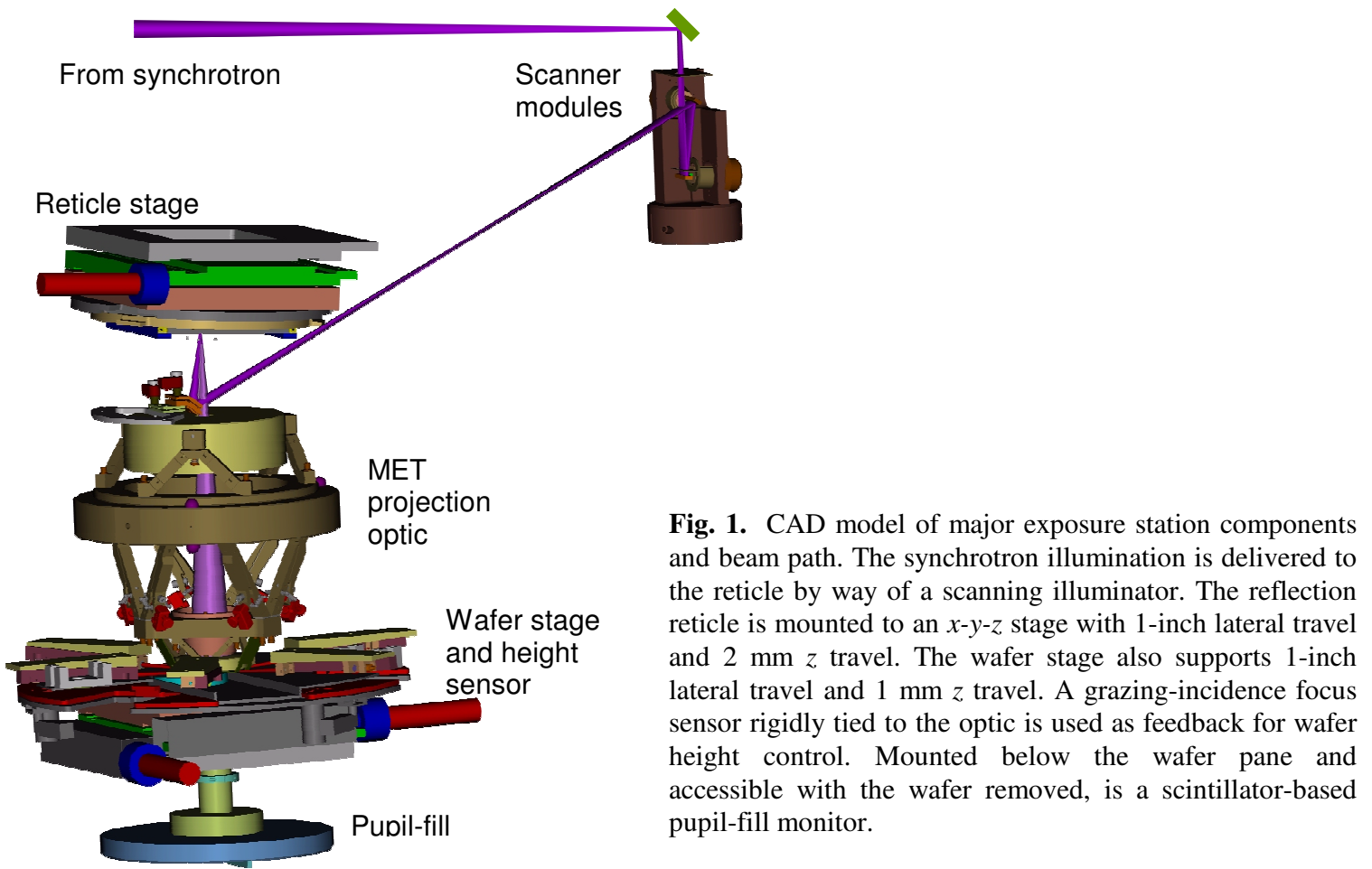

Figure 1 shows a CAD model depicting the major components of the exposure station as well as the EUV beam path. The system is described in detail in Ref. [5]. Using effectively coherent undulator radiation as the source, the system relies on a scanning illuminator [14] to provide lithographically relevant coherence (pupil fill). Figure 2 shows a variety of EUV pupil fills recorded using the in-situ pupil fill monitor located below the wafer plane. Visualizing the pupil fill after passage through the imaging optic allows the relative alignment of the illuminator to the imaging optic to be verified as well. The illuminator can generate arbitrary pupil fills covering a range up to $1.2 \sigma$ in $x$ and $0.8 \sigma$ in $y$. Also, the central obscuration alone can be illuminated, enabling frequency doubling from the mask to the wafer.
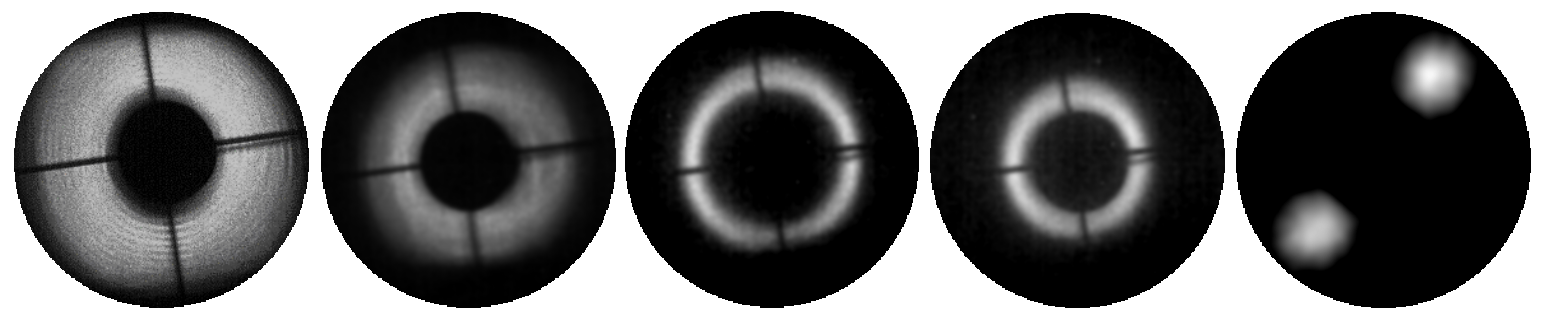

Fig. 2. EUV pupil fills recorded through the MET exposure system using the in-situ pupil-fill monitor. The illuminator can access a $\sigma$ range of up to 1.2 in $x$ and 0.8 in $y$. 
Although originally envisaged exclusively as a resist evaluation tool, it quickly became apparent that this unique high-NA EUV exposure tool would be useful in a wide variety of EUV-specific studies including critical mask issues. To more effectively support mask studies, the system was recently upgraded to include a reticle load-lock system with manual transfer (Fig. 3). With this system, masks can be exchanged and ready to print within 30 minutes. This rapid transfer time is enabled not only by the load-lock itself, but also by the in-situ reticle metrology system that allows the new reticle to be accurately positioned in five degrees of freedom. To date, 11 masks have been tested in the system.

\section{PREDICTED RESOLUTION LIMIT}

With a NA of 0.3 , the MET optical system is expected to have a Rayleigh resolution of $27 \mathrm{~nm}$. The programmable coherence illuminator used on the MET system at Berkeley, however, enables the $\mathrm{k}_{1}$ factor to be pushed significantly below 0.61 . Figure 4 shows the modeled aerial image contrast transfer function for vertical lines and spaces for three different pupil fills. In all cases, the EUV measured wavefront $[15,16]$ is used in the modeling. The results show that under standard annular illumination $(0.3<\sigma<0.7)$ the resolution knee occurs at about $23 \mathrm{~nm}$. Going to 45-degree dipole illumination, the resolution knee is pushed out to approximately $20 \mathrm{~nm}$ and the aerialimage contrast generally enhanced. Ultimate resolution on vertical lines can be achieved by going to $x$-dipole illumination with an offset $\sigma$ of 1 . In this case the resolution knee is all the way down to $12.5 \mathrm{~nm}$. The resolution for the $x$-dipole case could be further pushed to $12 \mathrm{~nm}$ if the pole size were to be reduced from the $0.2 \sigma$ radius used in Fig. 4.

The $x$-dipole case shows a contrast dead band in the 20 to $35 \mathrm{~nm}$ range. This is a result of the interaction between the diffracted orders from the mask pattern and the central obscuration in the optic. Moreover, the $x$-dipole case can be shown to suffer from very poor performance on horizontal features. Both these problems can be overcome by using the 45-degree dipole condition while still achieving a resolution knee of $20 \mathrm{~nm}$, considerably better than any currently available chemically amplified resist.

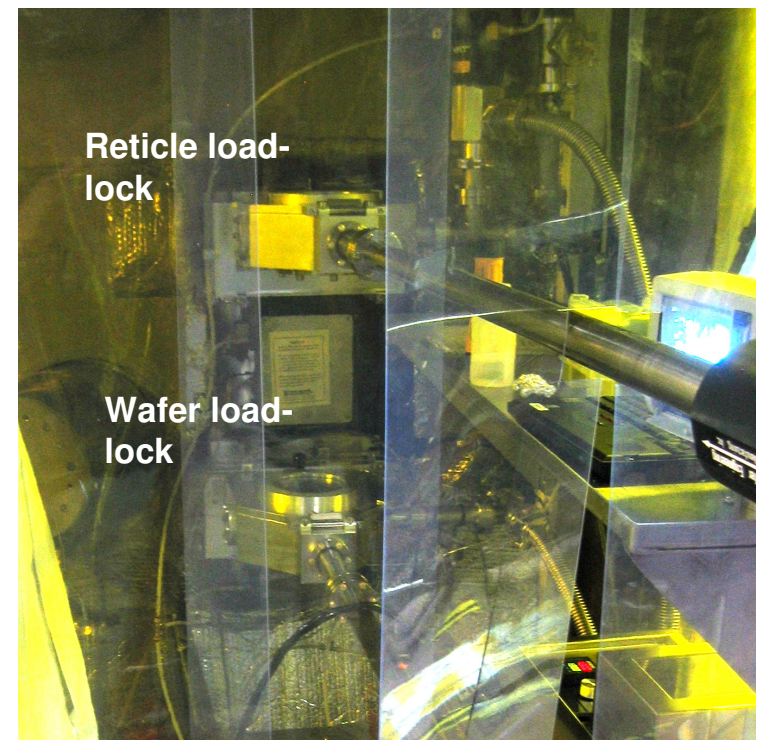

Fig. 3. Photograph of the transfer and PEB area for the exposure station. The area is temperature controlled and filtered for both particles and amine contamination.

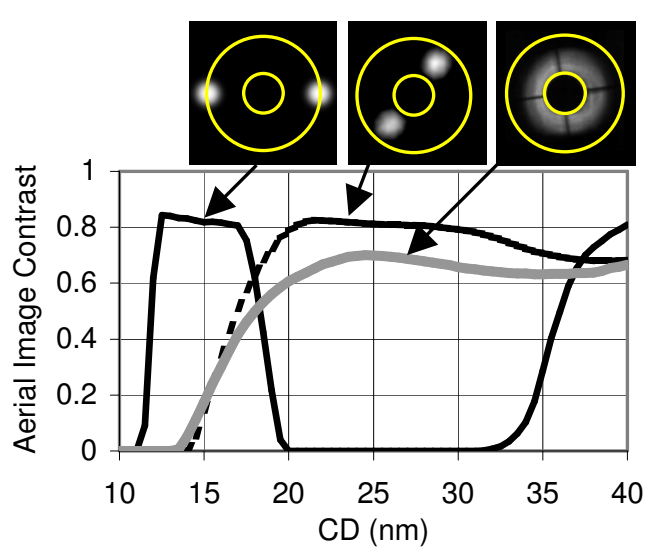

Fig. 4. Modeling of the aerial image contrast transfer function for three different pupil fills.

\section{PERFORMANCE CHARACTERIZATION}

With the goal of being a resist and mask test bed, it is crucial that the performance of the system itself be well characterized under some baseline process. Due to its long track record in EUV research, we chose Rohm and Haas $E U V-2 D$ resist as the baseline process. This well characterized resist [17] has been the workhorse of lower-NA EUV research in the United States. Figure 5 shows a series of exposures in a 125-nm-thick layer of $E U V-2 D$. The illumination conditions were annular with an inner $\sigma$ of 0.3 and an outer $\sigma$ of 0.7 . The results show the imaging to break down at about the 45-nm level. This is significantly worse than the expected resolution limit of the optic and can likely be attributed to resolution limits of the resist itself which had previously been predicted to be in the 40 to 45 -nm range $[18,19]$. 
Since printing operations began in March 2004, approximately 120 resists have been tested in the Berkeley exposure tool. One of the most promising resist in terms of resolution has been Rohm and Haas MET- $1 K$ resist (XP3454C). Figure 6 shows a series of equal-line-space patterns printed in 125-nm-thick layer of resist this resist. The illumination conditions are the same as for the images in Fig. 5 (annular 0.3-0.7). This experimental chemically amplified resist shows that the optic is capable of at least 30-nm printing and verifies the assertion that the printing limits observed in Figs. 5 are indeed due to the resist.
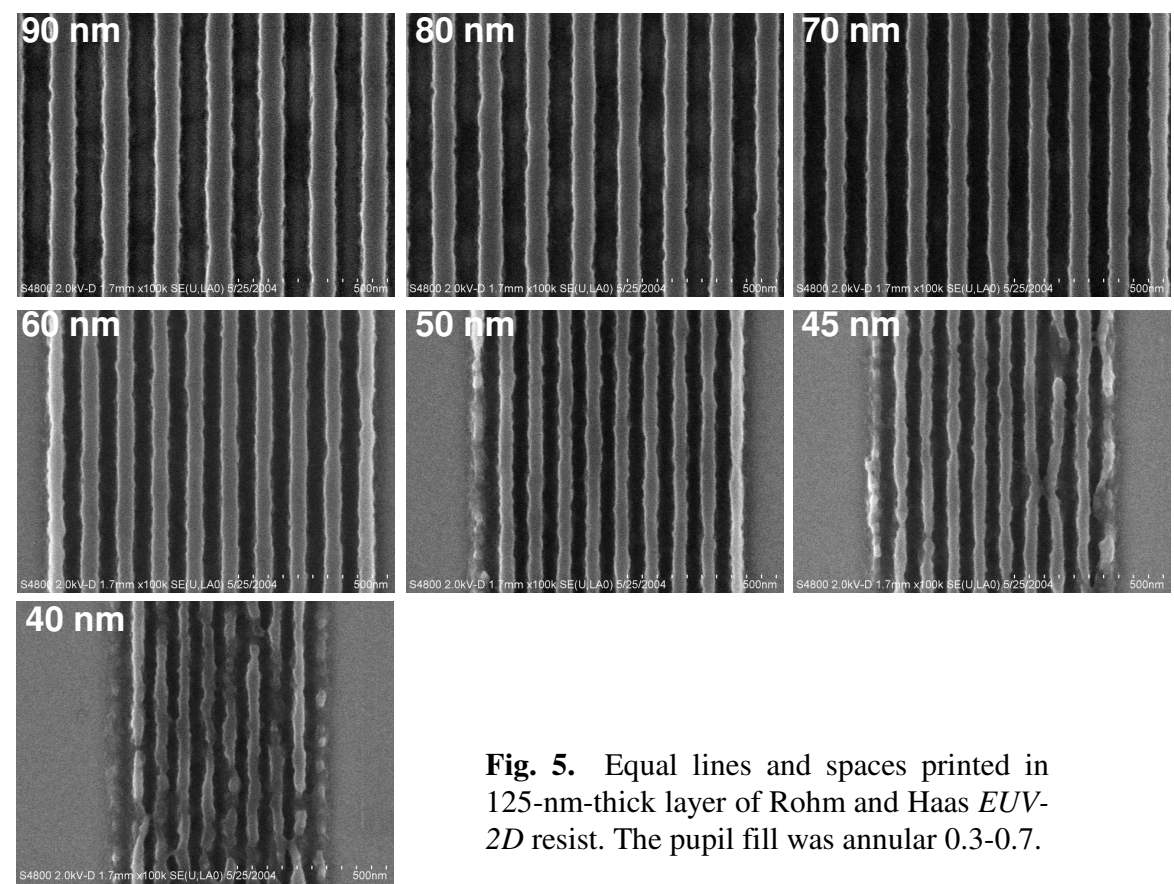

Fig. 5. Equal lines and spaces printed in 125-nm-thick layer of Rohm and Haas EUV$2 D$ resist. The pupil fill was annular 0.3-0.7.
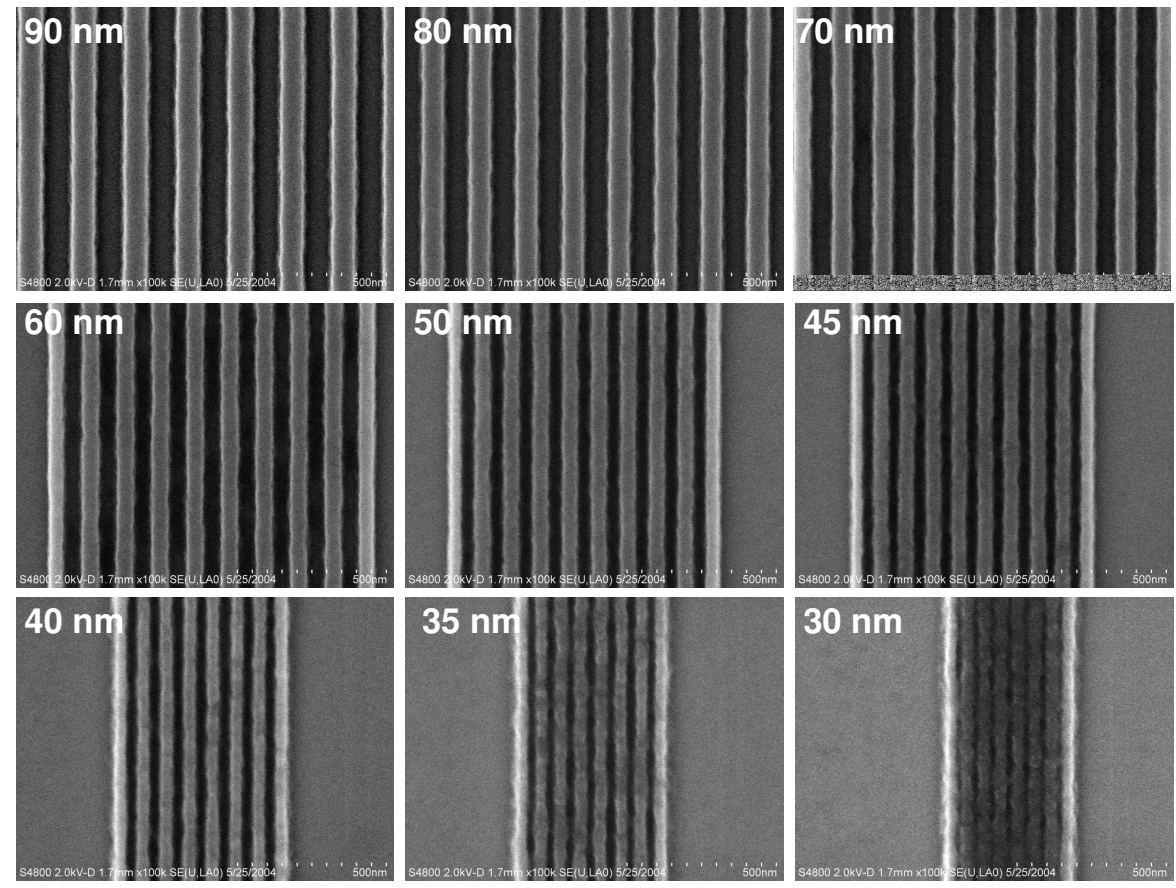

Fig. 6. Equal lines and spaces printed in 125-nm-thick layer of Rohm and Haas MET- $1 K$ resist. As in Fig. 5, the pupil fill was annular 0.3-0.7. 
A more quantitative comparison of $E U V-2 D$ and $M E T-1 K$ can be achieved through process window analysis. Figure 7 shows the direct process window comparison for 50-nm features. The top row shows the results for $E U V-2 D$ and the bottom row for MET- $1 K$. In $E U V-2 D$ the depth of focus is only $90 \mathrm{~nm}$ at an exposure latitude limit of below $9 \%$. $M E T-1 K$ on the other hand displays a depth of focus of $200 \mathrm{~nm}$ at an exposure latitude of $10 \%$. In all cases, the process window size is based on $\pm 10 \%$ CD change. The Bossung curves in the second column are based on $5 \%$ dose steps.
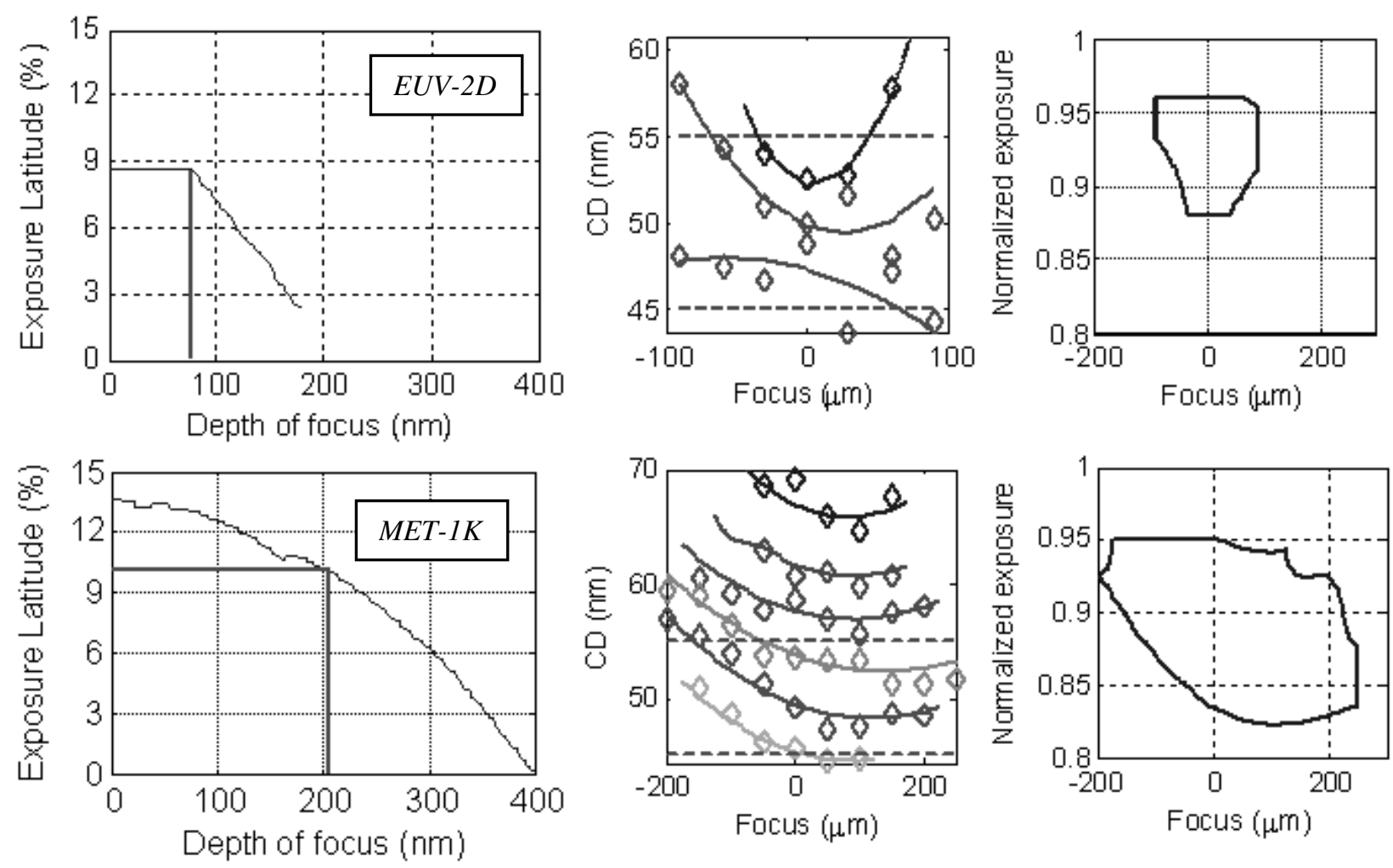

Fig. 7. Direct process window comparison on 50-nm lines space features between $E U V-2 D$ and $M E T-1 K$ resist. The exposure conditions are as described in Figs. 5 and 6 . The process window constraints are set to $\pm 10 \% \mathrm{CD}$ change. The Bossung curves are based on $5 \%$ dose steps.
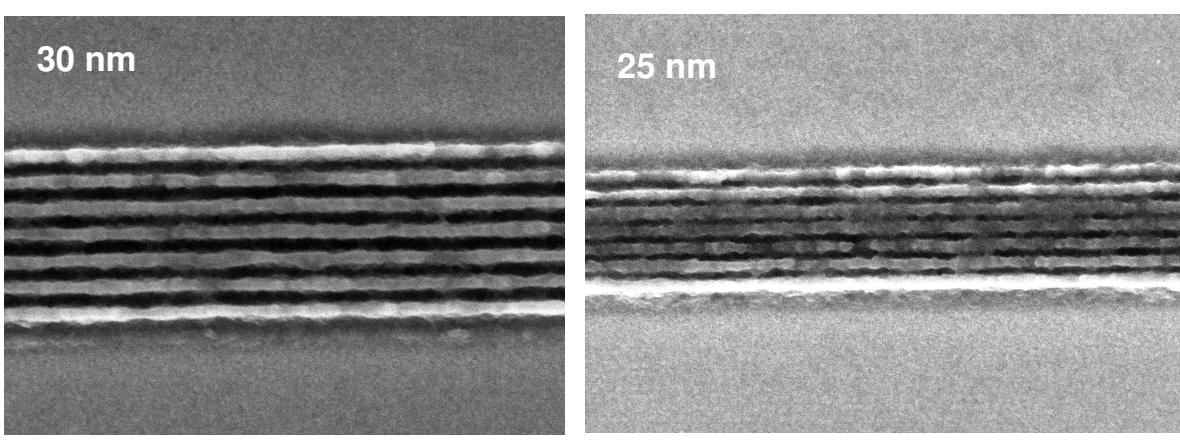

Fig. 8. Printing of $30-\mathrm{nm}$ and $25-\mathrm{nm}$ equal lines and spaces in $M E T-1 K$ resist using monopole illumination.

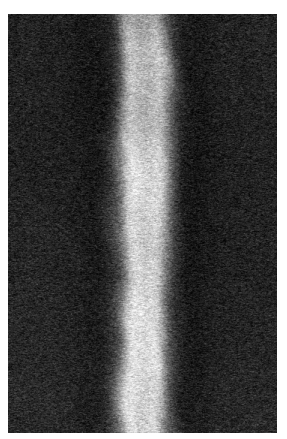

Fig. 9. Printing of 28.8-nm isolated line with $3.2 \mathrm{~nm}$ LER. The line is coded on the mask as a $50-\mathrm{nm}$ isolated line. 
Based on Fig. 4, one might expect the performance of MET-1K to improve slightly by employing dipole, or its near equivalent, monopole, illumination. Figure 8 shows prints of $30-\mathrm{nm}$ and $25-\mathrm{nm}$ equal lines and spaces printed in $M E T-1 K$ under monopole illumination. The pole offset radius was 0.6 at 45 degrees and the pole radius was 0.2 . A slight improvement is indeed seen, however, the 30-nm resolution cutoff is still evident suggesting that the limit is indeed resist induced. It is also well known that the resolution of isolated features can be improved through an exposure based slimming process. Attempting this in MET-1K using conventional illumination and working with a coded 50-nm isolated line, we achieve the results shown in Fig. 9. This printed $28.8 \mathrm{~nm}$ line has an LER of $3.2 \mathrm{~nm}$ as measured over a length equal to 4 times the CD. Again we find the resolution cutoff to be close to $30 \mathrm{~nm}$.

Given the markedly superior performance of $M E T-1 K$ over $E U V-2 D$, it has become our resist of choice for continued characterization of the system. The ability to control focus is crucial to achieving optimal results and to obtaining useful focus-exposure matrix data. One way to verify this performance is to carefully monitor printing performance on small features taking small steps through focus. Figure 10 shows a series of 40-nm lines and spaces in $M E T-1 K$ resist through focus. The focus step sizes are all nominally $30-\mathrm{nm}$ and the illumination was annular $0.3<\sigma<$ 0.7. The smooth behavior of the printing performance observed in the images and quantified in the line-edge roughness (LER) and CD plot demonstrate the fine focus control capabilities of the Berkeley exposure tool.
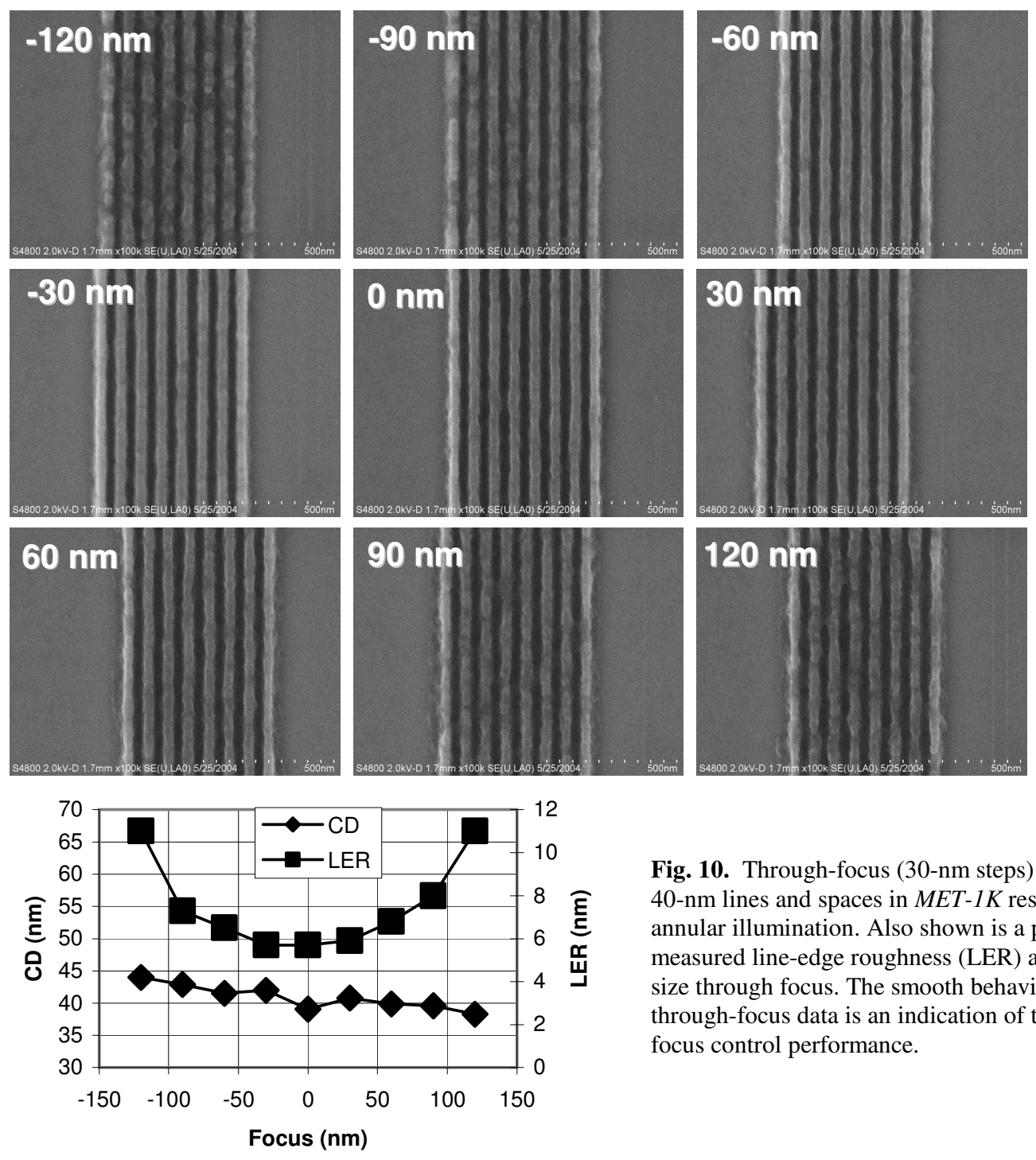

Fig. 10. Through-focus (30-nm steps) series of 40-nm lines and spaces in $M E T-1 K$ resist under annular illumination. Also shown is a plot of the measured line-edge roughness (LER) and feature size through focus. The smooth behavior of the through-focus data is an indication of the good focus control performance. 
Another important tool performance metric is die-todie dose control. To characterize this we exposed 100 identical die (same dose and focus) and then measure the $\mathrm{CD}$ and LER across the wafer. Figure 11(a) shows the measured $\mathrm{CD}$ for features coded as 60-nm across all 100 die. The error bars correspond to the variation observed from repeated measurements of the same die as well as line-to-line variations within a single image. The measured die-to-die rms $\mathrm{CD}$ variation is $1.2 \mathrm{~nm}$, which based on a previously measured CD sensitivity to dose of $0.83 \mathrm{~nm}$ per $\%$ dose for 60-nm features, corresponds to a rms die-to-die dose variation of $1.5 \%$. Figure 11(b) shows the LER from these same prints. Here we see the die-to-die LER variation to be significantly smaller than the observed line-to-line LER variation depicted by the error bars.

MET-1K's relatively low cross-linking threshold makes it unsuitable, however, for the characterization of flare. Because flare tests do not require particularly high resolution, we continue to use $E U V-2 D$ in these cases. As described elsewhere in these proceedings [20], the flare of the MET optic has been lithographically characterized to match the predicted value of $7 \%$ in a 500-nm line. We note, however, that achieving this level of flare requires the individual die on the wafer to be sufficiently far apart such that flare from adjacent die becomes inconsequential. This spacing was found to be approximately $1 \mathrm{~mm}$.
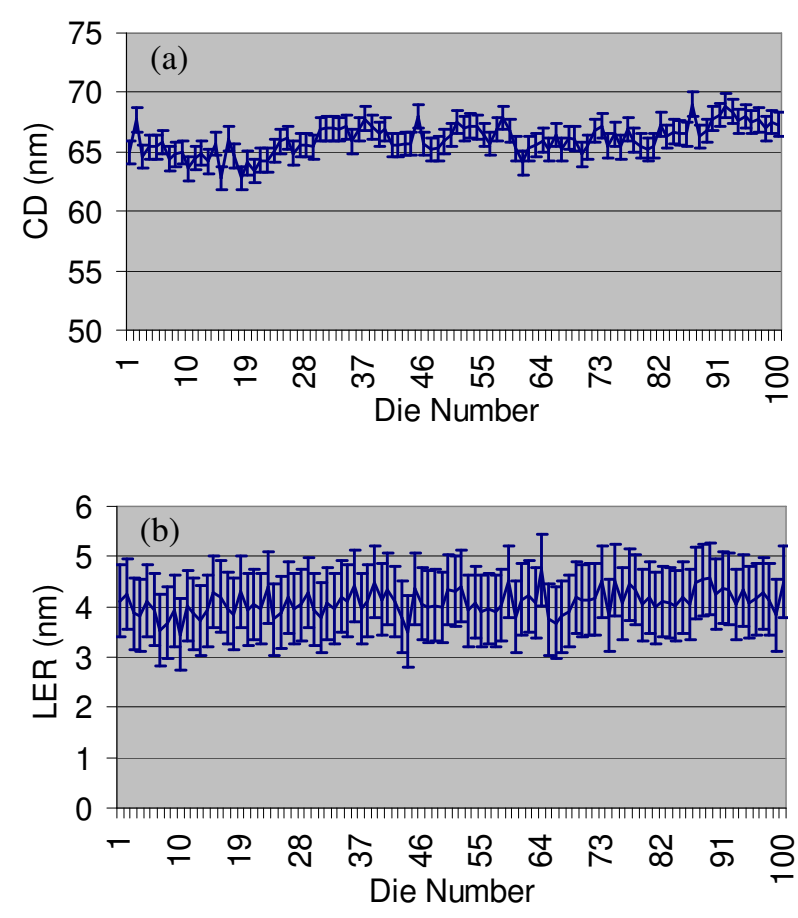

Fig. 11. Die-to-die reproducibility of CD (a) and LER (b) on 60-nm coded lines and spaces printed in MET$1 K$ resist.

\section{SUMMARY}

The 0.3-NA MET based micro-exposure station has been operational at Lawrence Berkeley National Laboratory's Advanced Light Source synchrotron radiation facility for approximately one year. During that time, a total of 11 masks and approximately 120 resists have been tested. Constrained by current resist limits, equal line-space printing approaching 25-nm has been demonstrated. System characterization has demonstrated focus control capabilities of better than $30 \mathrm{~nm}$ and dose control of $1.5 \%$. The programmable illuminator design allows for printing down to $\mathrm{k}_{1}$ factors approaching $0.25(12 \mathrm{~nm})$, but limitations of current chemically amplified resists prevent the exploitation of these capabilities.

\section{ACKNOWLEDGEMENTS}

The authors are greatly indebted to Robert Brainard and Thomas Koehler of Rohm and Haas for resist and process support. This research was performed at Lawrence Berkeley National Laboratory and supported by SEMATECH. Lawrence Berkeley National Laboratory is operated under the auspices of the Director, Office of Science, Office of Basic Energy Science, of the US Department of Energy.

\section{REFERENCES}

1. R. Stulen and D. Sweeney, "Extreme ultraviolet lithography," IEEE J. Quantum Electron. 35, 694-699 (1999).

2. J. Goldsmith, K. Berger, D. Bozman, G. Cardinale, D. Folk, C. Henderson, D. O'Connell, A. Ray-Chaudhuri, K Stewart, D. Tichenor, H. Chapman, R. Gaughan, R. Hudyma, C. Montcalm, E. Spiller, J. Taylor, J. Williams, K. Goldberg, E. Gullikson, P. Naulleau, J. Cobb, "Sub-100-nm lithographic imaging with an EUV 10× microstepper," Proc. SPIE 3676, 264-271 (1999). 
3. K. Hamamoto, T. Watanabe, H. Tsubakino, H. Kinoshita, T. Shoki, M. Hosoya, "Fine pattern replication by EUV lithography," Journal of Photopolymer Science \& Technology 14, 567-572 (2001).

4. P. Naulleau, K. Goldberg, E. Anderson, D. Attwood, P. Batson, J. Bokor, P. Denham, E. Gullikson, B. Harteneck, B. Hoef, K. Jackson, D. Olynick, S. Rekawa, F. Salmassi, K. Blaedel, H. Chapman, L. Hale, P. Mirkarimi, R. Soufli, E. Spiller, D. Sweeney, J. Taylor, C. Walton, D. O'Connell, R. Stulen, D. Tichenor, C. Gwyn, P. Yan and G. Zhang, "Sub-70-nm EUV Lithography at the Advanced Light Source Static Microfield Exposure Station Using the ETS Set-2 Optic,” J. Vac. Sci. \& Technol. B 20, 2829-2833 (2002).

5. P. Naulleau, K. Goldberg, E. Anderson, K. Bradley, R. Delano, P. Denham, R. Gunion, B. Harteneck, B. Hoef, H. Huang, K. Jackson, M. Jones, D. Kemp, J. Liddle, R. Oort, A. Rawlins, S. Rekawa, F. Salmassi, R. Tackaberry, C. Chung, L. Hale, D. Phillion, G. Sommargren, H. Taylor, "Status of EUV micro-exposure capabilities at the ALS using the 0.3-NA MET optic," Proc. SPIE 5374, 881-891 (2004).

6. P. Naulleau, K. Goldberg, J. Cain, E. Anderson, P. Denham, K. Jackson, S. Rekawa, F. Salmassi, G. Zhang, "EUV Microexposures at the ALS using the 0.3-NA MET Optic," J. Vac. Sci. \& Technol. B 22, 2962-2965 (2004).

7. A. Brunton, J. S. Cashmore, P. Elbourn, G. Elliner, M. C. Gower, P. Gruenewald, M. Harman, S. Hough, N. McEntee, S. Mundair, D. Rees, P. Richards, V. Truffert, I. Wallhead, M. D. Whitfield, "High-resolution EUV imaging tools for resist exposure and aerial image monitoring," these proceedings.

8. H. Oizumi, Y. Tanaka, I. Nishiyama, H. Kondo, K. Murakami, "Lithographic performance of high-numericalaperture (NA=0.3) EUV small-field exposure tool (HINA)," these proceedings.

9. D. Attwood, G. Sommargren, R. Beguiristain, K. Nguyen, J. Bokor, N. Ceglio, K. Jackson, M. Koike, and J. Underwood, "Undulator radiation for at-wavelength interferometry of optics for extreme-ultraviolet lithography," Appl. Opt. 32, 7022-7031 (1993).

10. C. Chang, P. Naulleau, E. Anderson, and D. Attwood, "Spatial coherence characterization of undulator radiation," Opt. Comm. 182, 24-34 (2000).

11. P. Naulleau, K. Goldberg, P. Batson, J. Bokor, P. Denham, and S. Rekawa, "A Fourier-synthesis custom-coherence illuminator for EUV microfield lithography,” Appl. Opt. 42, 820-826 (2003).

12. J. Taylor, D. Sweeney, R. Hudyma, L. Hale, T. Decker, G. Kubiak, W. Sweatt, N. Wester, "EUV Microexposure Tool (MET) for near-term development using a high NA projection system," 2nd International EUVL Workshop October 19-20, 2000 (www.sematech.org/public/resources/litho/euvl/euvl2000/documents/707_SYS07_taylor.pdf)

13. R. Hudyma, J. Taylor, D. Sweeney, L. Hale, W. Sweatt, N. Wester, "E-D characteristics and aberration sensitivity of the Microexposure Tool (MET)," 2nd International EUVL Workshop October 19-20, 2000 (http://www.sematech.org/public/resources/litho/euvl/euvl2000/documents/hudyma.pdf).

14. P. Naulleau, P. Denham, B. Hoef, and S. Rekawa, "A design study for synchrotron-based high-numerical-aperture scanning illuminators," Opt. Comm. 234, 53-62 (2004).

15. K. Goldberg, P. Naulleau, P. Denham, S. Rekawa, K. Jackson, J. Liddle, E. Anderson, "EUV interferometric testing and alignment of the 0.3 NA MET optic," Proc. SPIE 5374, 64-73 (2004).

16. K. Goldberg, P. Naulleau, P. Denham, S. Rekawa, K. Jackson, E. Anderson and J. Liddle, "At-Wavelength Alignment and Testing of the 0.3 NA MET Optic,” J. Vac. Sci. \& Technol. B 22, 2956-2961 (2004).

17. S. Robertson, P. Naulleau, K. Goldberg, D. O'Connell, K. McDonald, S. Hansen, T. Delano, K. Brown, R. Brainard, "Calibration of EUV-2D photoresist simulation parameters for accurate predictive modeling," Proc. SPIE 5037, 900-905 (2003).

18. P. Naulleau, "Verification of point-spread function based modeling of an EUV photoresist," Appl. Opt. 43, 788-792 (2004).

19. S. Lee, D. Tichenor, P. Naulleau, D. O'Connell, "Lithographic Aerial Image Contrast Measurement in the EUV Engineering Test Stand," J. Vac. Sci. \& Technol. B 20, 2849-2852 (2002).

20. J. Cain, P. Naulleau, C. Spanos, "Lithographic measurement of EUV flare in the 0.3-NA MET optic," these proceedings. 